\title{
Screening for Depression and Anxiety Symptoms among a Sample of Working Syrian Refugees in Egypt
}

\author{
${ }^{1}$ Walaa Sabry, ${ }^{2}$ Nayera Mostafa, ${ }^{2}$ Maha Wahdan \\ ${ }^{1}$ Institute of Psychiatry, ${ }^{2}$ Community, environmental and occupational Medicine department \\ Faculty of Medicine, Ain Shams University, Cairo, Egypt
}

Received: February. 2018 Accepted: May, 2018

\begin{abstract}
Background: Since the Arab spring, a large number of Syrian refugees arrived to Egypt. The majority of these refugees faced numerous traumatic events both in their country of origin and while moving from it. This raised the prevalence rates of depression and anxiety disorders among refugees than other populations. There are very few studies regarding the mental health of these vulnerable populations in Egypt. Objective: This study aims to screen for depressive and anxiety symptoms among a sample of working Syrian refugees in Cairo, Egypt and to estimate their socio-demographic and employment correlates. Method: A cross sectional study with convenient method of sampling was carried out. The sample was recruited from a primary healthcare center. Socio-demographic data were identified using designed questionnaires. Depressive and anxiety symptoms were evaluated using Beck Depression inventory (BDI) and Taylor anxiety scales respectively. Results: Ninety-four Syrian worker refugees participated in the current study. Depressive symptoms were prevalent among $63 \%$ of the studied sample and anxiety symptoms were found among $89 \%$ of them. The refugee's duration of being away from his/her country represents a statistical significant factor that was associated with higher rates of depressive symptoms. None of other sociodemographic \& employment factors were found to be associated with the rates of depressive or anxiety symptoms among the study sample. Conclusion: Syrian refugees are at high risk of developing depressive and anxiety symptoms. Increased attention from primary and mental health care services to adequately support Syrian refugees' mental health needs are urgently needed.
\end{abstract}

Keywords: depression, anxiety, Syrian refugees, Egypt.

Corresponding author: Nayera Samy Mostafa Email: Nayera_samy@med.asu.edu.eg

\section{Introduction:}

According to the last World Bank report, about 65 million people - one percent of the world's population live in forced displacement. ${ }^{1}$ As opposing to economic migrants who travel in a search for better economic opportunities, Refugees are usually facing extremely challenging psychological, social and financial stressors. ${ }^{2}$ Till the 1970 s, there were a great lack in scientific research studying the

The Egyptian Journal of Community Medicine nature, prevalence and risk factors; (including economic factors of the host country) for mental health problems amongst refugees worldwide. In the following two decades, several epidemiological studies on the refugee mental health field had taken place. However, they mainly focused on PTSD and studies on depression and anxiety remain scarce. ${ }^{3,4}$ Many factors can

$\begin{array}{llll}\text { Vol. } 38 & \text { No. } 1 & \text { January } & 2020\end{array}$


contribute to refugee's mental health problems; including socioeconomic status, financial and employment constrains with low financial security and sometimes without any health insurance, higher risk of poverty and social exclusion, resettlement and acculturation challenges, multiple responsibilities, discriminatory treatment, and difficulty obtaining services in a timely manner due to language differences. In addition, the impact of vocational factors like job shift, job availability, working hours, monthly income and job satisfaction; could have a detrimental impact on refugees' mental health. ${ }^{5}$ Employment is considered one of the main elements of successful social and financial settlement for refugees, allowing economic independence, which is known to have mental health effects, helping language learning and creating contacts or bridges with the host community. ${ }^{6}$

Since 2011, Syrian Arab Republic and Syrian citizens, had faced a drastic change from being one of largest refugee hosting country, to becoming the second largest refugee producing country with an estimated 2.47 million Syrians already displaced outside their country. According to the United Nation High Commissioner for Refugees (UNHCR)'s statistics in, Egypt currently hosts 128, 034 Syrian refugees of which 78,673 residing in Cairo. ${ }^{7}$

Despite the high rates of mental health problems among refugees and the wide range of studies investigated these problems worldwide ${ }^{8-10}$; only few studies had examined the degree to which the Syrian crisis could affect the mental status of Syrian refugees settled in Egypt. ${ }^{11}$ The reason behind that may be due to the fact that; the huge burden aroused from the mass movement of refugee populations to Arab World host countries, puts mental health issues on the lowest priority level when compared to other unmet nutritional, health, financial and employment needs. And this is worsened by the economic difficulties facing most of Arab World countries. Thus, screening for these problems is very essential for early diagnosis and management.

The above finding highlights the importance of addressing and studying this issue, which motivated the study team aimed to screen for depressive and anxiety symptoms and to identify possible sociodemographic correlates with depression and anxiety among a sample of Syrian refugees in Cairo, Egypt.

\section{Method}

This is a cross sectional study that was carried out in outpatient clinics, Ain Shams University Hospitals (Egypt). The study was conducted in accordance with the guidelines of the Research and Ethics Committee of the Institute of Psychiatry, Ain Shams University.

Study sample: A convenience sample of 94 employed refugees were collected during the period between July to September, 2017 in Cairo. The exclusion criteria were to be younger than 18 years of age, or to have immigrated before the beginning of Syrian conflicts. Individuals who was having one or more major depressive episodes (MDE) before the onset of the war in 2011 or having any past history of other psychiatric illnesses or receiving any psychotropic medications. We also excluded all non-working refugees to eliminate the impact of unemployment on depression and anxiety. Calculation of sample size: A target number of 100 participants were obtained using $95 \%$ CI with an accepted margin of error $\pm 6 \%$ and based on the prevalence of depressions previously found on a population of Syrian refugees in 
Table 1: Socio-demographic data of the study sample $(n=94)$

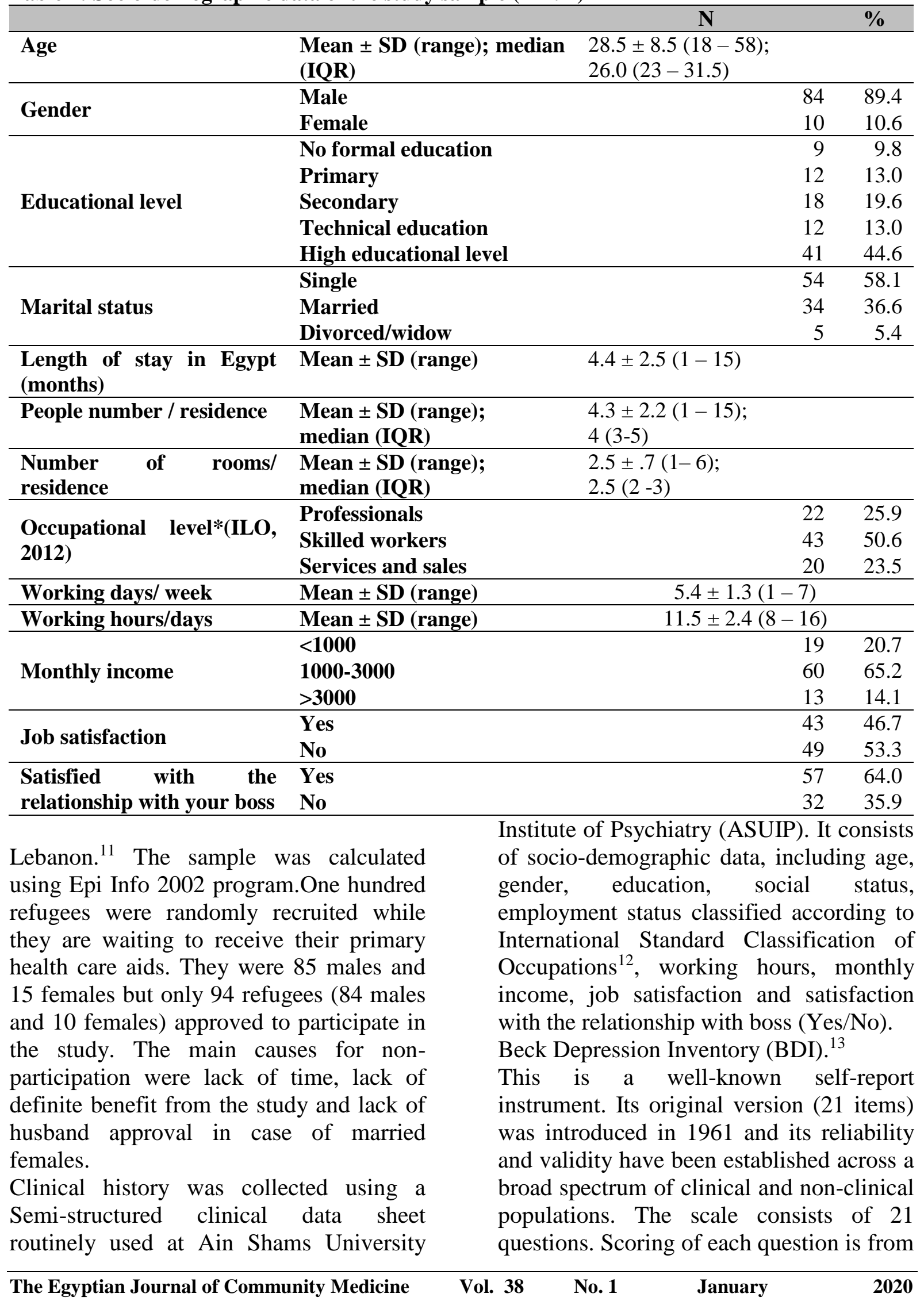


zero to 3 , and the total score ranges from zero to 63, subdivided into no depression (0-20), mild depression (21-29), moderate depression (30-38) and severe depression (39-63). The Arabic version of the BDI was used in this study. ${ }^{14}$

Taylor manifest anxiety scale ${ }^{15}$ : It is translated and validated in Arabic by Fahmi, Ghali, and Meleka ${ }^{16}$. It assesses the subject's awareness of estimate and willingness to report emotional habitual response rather than feeling at the time of completion of the scale. It consists of 50 items. Interpretation: zero-16: normal, 1724: mild, 25-35: moderate, 36-50: severe.

\section{Data Analysis:}

Data were analyzed using SPSS version 20 for Windows. Prior to analysis, the data was checked for accuracy of data entry and missing values.

Normality of the continuous variables was checked through the KolmogorovSmirnov test (KS). It was found work duration, working hours, working days, people numbers in residence and number of persons in room (crowding index) were not normally distributed.

The results were tabulated, grouped and statistically analyzed using the suitable statistical parameters. Continuous variables were presented as mean $\pm \mathrm{SD}$, and categorical variables as absolute numbers \& percentages while median and interquartile range was used for not normally distributed continuous data. Data were tested for statistical significance by using the chi-square test for categorical variables and the independent $t$ test for difference in means for normally distributed continuous variables and nonparametric tests were applied to continuous data which are not normally distributed $\mathrm{P}$ value was considered significant when $\mathrm{p}<0.05^{*}$ and highly significant when $\mathrm{P}<0.001 * *$

\section{Ethical consideration:}

Ethical approval was obtained from Ain Shams University Ethical Committee. In addition, administrative written approval was obtained from each refugee. Participants were educated about the study and the tools and their approval was collected.

\section{Results:}

Baseline socio-demographic characteristics of 94 respondents who agreed to participate in the study are presented in (table 1). Among them, 84 (89.4\%) were males. Most of them $54(58.1 \%)$ were single with mean age of $28.3 \pm 8.5$ (range 18-58) and the mean number of people / residence was $4.3 \pm 2.2$. A large proportion of participants were highly educated 41 (44.6\%). Nearly half of them $43(50.1 \%)$ were working in skilled job and at shops. The income of $43(65.2 \%)$ of participants was ranging between 1000- 3000 Egyptian pounds. Over half of the participants 49 (53.3\%) were not satisfied with their job, but $57(67.4 \%)$ were satisfied with the relationship with their boss.

A total of $53(63.1 \%, 95 \%$ CI: 52.4 $72.6 \%$ ) of participants were having depressive symptoms at the time of data collection where most of them $53.8 \%$ suffer from moderate depressive symptoms. Seventy-seven participants (89.5\%) had anxiety symptoms among whom $39(45.3 \%)$ had severe anxiety symptoms (table 2).

Occurrence rates for depression symptoms were statistically indifferent across age, marital status, occupation, SES, and education ( $p>0.05$ for all). Uncommonly, they did not even vary with gender. However, Refugees who stayed longer outside their country showed higher rates of depressive symptoms than short stayed refugees (table 3 ). 
Table 2: Occurrence rates of depression and anxiety symptoms among a sample of Working Syrian Refugees in Egypt $(n=94)$

\begin{tabular}{|c|c|c|c|}
\hline & & $\mathbf{N}$ & \\
\hline Beck Depression Inventory score & Mean \pm SD (range) & \multicolumn{2}{|c|}{$14.49 \pm 9.30(0-36)$} \\
\hline \multirow{2}{*}{ Depressive symptoms } & No & 31 & 36.9 \\
\hline & Yes & 53 & 63.1 \\
\hline \multirow{4}{*}{ Severity of depressive symptoms } & No & 31 & 36.9 \\
\hline & Mild & 17 & 20.2 \\
\hline & Moderate & 19 & 22.6 \\
\hline & Severe & 17 & 20.2 \\
\hline Taylor Anxiety scale & Mean \pm SD (range) & \multicolumn{2}{|c|}{$26.99 \pm 8.32(6-43)$} \\
\hline \multirow{2}{*}{ Anxiety symptoms } & No & 9 & 10.5 \\
\hline & Yes & 77 & 89.5 \\
\hline \multirow{5}{*}{ Severity of Anxiety symptoms } & No & 9 & 10.5 \\
\hline & Mild & 8 & 9.3 \\
\hline & Moderate & 22 & 25.6 \\
\hline & Severe & 8 & 9.3 \\
\hline & Extreme & 39 & 45.3 \\
\hline
\end{tabular}

On the other hand, anxiety rates were not significantly associated with most of sociodemographic factors and occupational history except number of rooms in residence place $(\mathrm{P}=.013)$ and satisfaction with the relationship with boss $(\mathrm{P}=.047)$ as detailed in (table 4).

\section{Discussion:}

Depression is the third leading cause of disability-adjusted life years (DALYs) in all age categories for both genders, as per the World Health Organization (WHO). ${ }^{17}$ However, till now, only few studies had assessed the degree to which the Syrian crisis could affect the mental health of Syrian refugees settled in the Arab World. ${ }^{11,18}$ In contrast to Western world, where language, social, cultural, lacking the knowledge about existing treatment possibilities and physical distance to mental health care services; are considered the main barriers for seeking mental health care $^{19-21}$, the main obstacle in Arab world for Syrian refugees to seek mental health service would be due to financial and economic reasons. This may hinder the ability for early diagnosis and management of mental health problems among refugees. To the best of our knowledge, the current study would be the first reflection of Syrian refugees in Egypt, using screening tools to assess for the emergence of a depressive and/or anxiety symptoms since the outbreak of the Syrian civil war in a sample of working Syrian refugees. As we considered that having a stable employment status could act as a potential protective parameter that could alleviate depressive and /or anxiety symptoms among war migrants.

The current study, indicates that refugees from Syria that resettled in Egypt following the war that started in 2011 have $63 \%$ occurrence rates for depressive symptoms. While the high prevalence of depression rates in our study; may reflect the truly surprisingly high levels of depressive symptoms encountered by this population, it may also be due to the fact that the BDI as a screening tool is too sensitive and not specific enough for a refugee population with recent exposure to war trauma.

Our results are slightly higher than the 
Table 3: Association between depressive symptoms and socio-demographic and occupational factors among the study sample $(\mathrm{n}=94)$

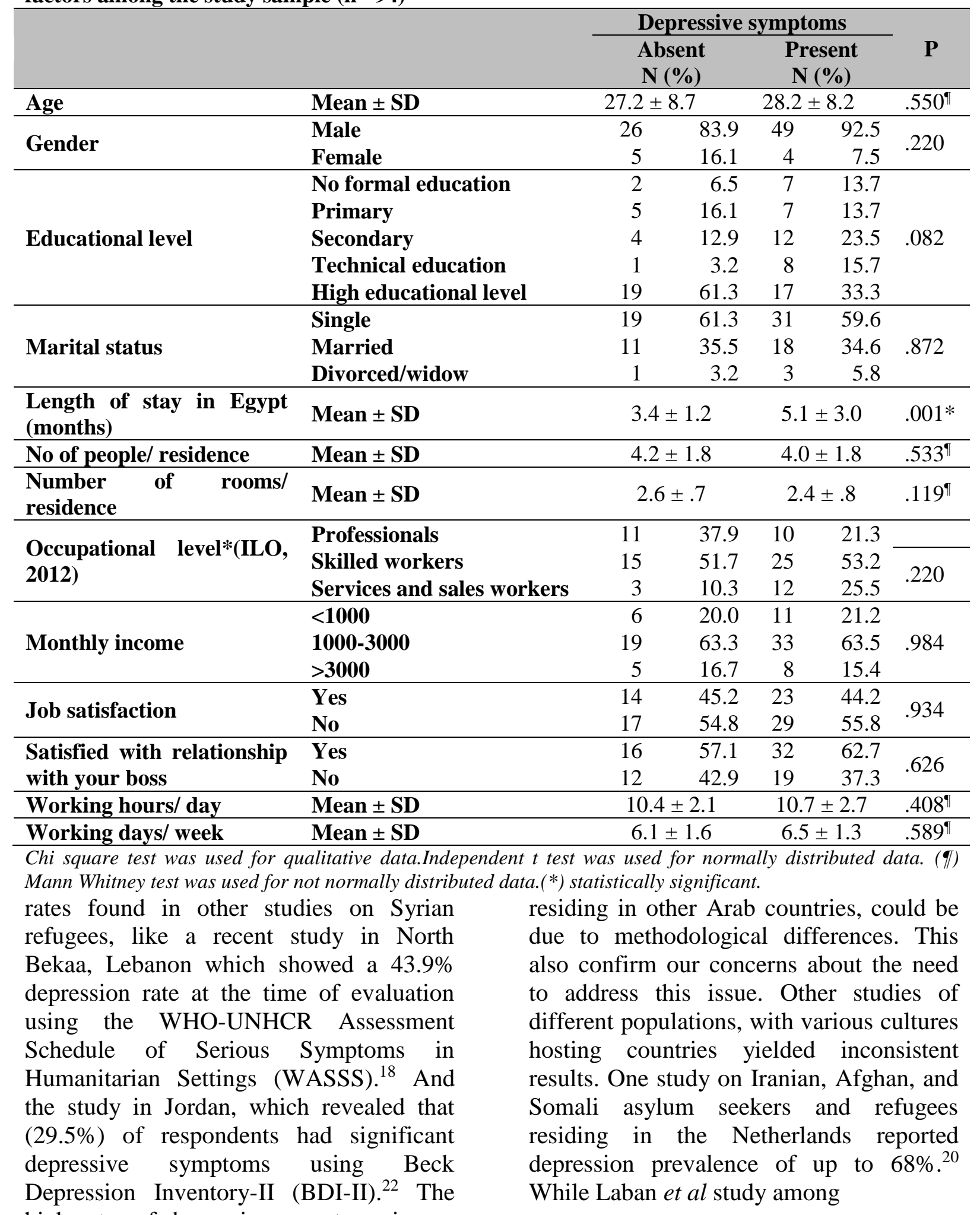

high rates of depressive symptoms in our sample compared to Syrian refugees 
Table 4: Association between anxiety symptoms and socio-demographic and occupational factors among Working Syrian Refugees in Egypt ( $n=94)$

\begin{tabular}{|c|c|c|c|c|c|c|}
\hline & \multicolumn{4}{|c|}{ Anxiety symptoms } & \multirow[b]{2}{*}{$\mathbf{P}$} \\
\hline & & \multicolumn{2}{|c|}{$\begin{array}{l}\text { Absent } \\
\mathbf{N}(\%)\end{array}$} & \multicolumn{2}{|c|}{$\begin{array}{l}\text { Present } \\
\text { N }(\%)\end{array}$} & \\
\hline Age & Mean \pm SD & \multicolumn{2}{|c|}{$27.2 \pm 8.0$} & \multicolumn{2}{|c|}{$28.3 \pm 8.3$} & $.822^{\mathbb{U}}$ \\
\hline \multirow{2}{*}{ Gender } & Male & 8 & 88.9 & 69 & 89.6 & \multirow{2}{*}{.947} \\
\hline & Female & $\mathbf{1}$ & 11.1 & 8 & 10.4 & \\
\hline \multirow{5}{*}{ Education } & No formal education & 1 & 11.1 & 8 & 10.5 & \multirow{5}{*}{.191} \\
\hline & Primary & $\mathbf{0}$ & $\mathbf{0 . 0}$ & 11 & 14.5 & \\
\hline & Secondary & 1 & 11.1 & 16 & 21.1 & \\
\hline & Technical education & $\mathbf{0}$ & $\mathbf{0 . 0}$ & 12 & 15.8 & \\
\hline & High educational level & 7 & 77.8 & 29 & 38.2 & \\
\hline \multirow{3}{*}{ Marital status } & Single & 5 & 55.6 & 43 & 56.6 & \multirow{3}{*}{.771} \\
\hline & Married & 3 & 33.3 & 29 & 38.2 & \\
\hline & Divorced/widow & 1 & 11.1 & 4 & 5.3 & \\
\hline $\begin{array}{l}\text { Length of stay in Egypt } \\
\text { (months) }\end{array}$ & Mean \pm SD & \multicolumn{2}{|c|}{$3.6 \pm 1.4$} & \multicolumn{2}{|c|}{$4.6 \pm 2.6$} & .619 \\
\hline Number of people/ residence & Mean \pm SD & \multicolumn{2}{|c|}{$6.3 \pm 4.2$} & \multicolumn{2}{|c|}{$4.2 \pm 1.8$} & .190 \\
\hline Number of rooms/ residence & Mean \pm SD & \multicolumn{2}{|c|}{$3.0 \pm .7$} & \multicolumn{2}{|c|}{$2.5 \pm .6$} & $.030 *$ \\
\hline \multirow{3}{*}{$\begin{array}{l}\text { Occupational } \\
\text { 2012) }\end{array}$} & Professionals & 2 & 28.6 & 17 & 23.9 & \multirow{3}{*}{.771} \\
\hline & Skilled workers & 4 & 57.1 & 35 & 49.3 & \\
\hline & $\begin{array}{l}\text { Services and sales } \\
\text { workers }\end{array}$ & 1 & 14.3 & 19 & 26.8 & \\
\hline \multirow{3}{*}{ Monthly income } & $<1000$ & 1 & 11.1 & 15 & 19.7 & \multirow{3}{*}{.269} \\
\hline & $1000-3000$ & 5 & 55.6 & 51 & 67.1 & \\
\hline & $>3000$ & 3 & 33.3 & $\mathbf{1 0}$ & 13.2 & \\
\hline \multirow{2}{*}{ Job satisfaction } & Yes & 6 & 66.7 & 31 & 40.8 & \multirow{2}{*}{$.139^{a}$} \\
\hline & No & 3 & 33.3 & 45 & 59.2 & \\
\hline \multirow{2}{*}{$\begin{array}{l}\text { Satisfied with relationship } \\
\text { with your boss }\end{array}$} & Yes & 8 & 88.9 & 47 & 64.4 & \multirow{2}{*}{$.140^{a}$} \\
\hline & No & 1 & 11.1 & 26 & 35.6 & \\
\hline Working hours/ day & Mean \pm SD & \multicolumn{2}{|c|}{$10.6 \pm 1.6$} & \multicolumn{2}{|c|}{$11.1 \pm 2.2$} & .482 \\
\hline Working days/ week & Mean \pm SD & \multicolumn{2}{|c|}{$6.8 \pm .4$} & \multicolumn{2}{|c|}{$6.6 \pm 1.1$} & .356 \\
\hline
\end{tabular}

Chi square test was used for qualitative data. Independent t test was used for normally distributed data.

(II) Mann Whitney test was used for not normally distributed data. (*) statistically significant.

Iraqi asylum seekers in the Netherlands, reported $34 \%$ prevalence rate of depressive symptoms among their participants. ${ }^{23}$ On the other hand, a large meta-analysis reported a very low prevalence rate of $5 \%$ for the 14 studies with at least 200 participants. $^{24}$ Several studies attributed these low rates to the lack of validity of the assessment tools, originally developed for Western population, when applied to refugees from underdeveloped countries, could lead to underestimated values. ${ }^{25-27}$
The high prevalence rates of anxiety symptoms in this study $(89.5 \%)$. High rates of anxiety among the Syrian refugees could be due to their high exposure to warrelated traumatic events during the Syrian conflict. But our study rates are higher than many others obtained from previous larger studies on refugees ${ }^{28-30}$, but these studies focused mainly on PTSD prevalence rates among refugees. Any comparison should, however, be done taking in consideration the different methodological aspects and the inclusion 
criteria between studies. Similarly, the high rates among our study population may be due to the use of screening tools (Taylor Anxiety scale). The main aim of the screening tool is not to provide a diagnosis, but rather to aid in the referral to a special mental health unit, which may help in early diagnosis and management.

On studying the association of sociodemographic and employment correlates with depression and anxiety rates among our sample, we found that both depression and anxiety rates were not significantly correlated with most of socio-demographic factors and occupational history. But only refugees who stayed longer outside their country; showed higher rates of depressive symptoms than short stayed refugees. This finding is still unclear with contradictory results in various studies. Some researchers confirmed the idea of improved mental health of resettled refugee populations over time. ${ }^{31}$ Similarly, Krupinski \& his colleagues ${ }^{32}$ noted that some Jewish refugees resettled in Australia had lower rates of mental health disorders, compared to other Eastern European refugee groups, despite their high level of exposure to traumatic events. And the study by Steel and colleagues ${ }^{33}$ who found that that mental health problems decreased steadily over time Vietnamese refugees resettled in Australia Further. In line with our results, other studies showed greater psychological impairment over time. Like a cross-sectional study conducted in the US which denoted high prevalence rates of mental health disorders among Cambodian refugees 20 years after resettlement, with $62 \%$ for PTSD and $51 \%$ for depression. ${ }^{34}$ This highlight the impact of war related trauma on mental health and it continue to be problematic many years post resettlement in some refugee groups and in some cases, it may increase over time. ${ }^{2}$
Although, different studies highlighted that employment (access, type, security and match to skill levels), housing (conditions, area and future options) and education (in country of origin, including access to language learning where necessary) are considered the main indicators for the proper integration of refugees in their host country and hence their mental wellbeing. ${ }^{35}$ None of other sociodemographic and employment factors were found to be significantly associated with depression and anxiety rates among our study sample. This may dente a good integration of Syrians among the Egyptian community.

\section{Conclusion:}

Our study shows that prevalence of mental ill health, in terms of anxiety and depression, is highly elevated among refugees from Syria. Our study has implications for both for government and non-government funded organizations who should take in consideration the need for development of assistance programs beyond the initial arrival period. On the basis of the above results, we highly recommend early screening, diagnosis and management of mental health problems among Syrians. Further studies are needed include additional factors, large size population and diagnostic tools. Prompt measures have to be taken to better identify and prevent mental health problems of this fragile population.

This study is considered a highlight for the psychological problems of Syrian refugees in Egypt. An essential problem due to their increasing number in the Egyptian community, and stressful economic burden. This work is considered of value because of the scarcity of this type of study within the Egyptian community. 


\section{Limitations}

The current work used only simple tools to screen for depression \& anxiety as a result of shortage of time due to the high flow rate of patients at outpatient clinic of the institute of psychiatry. Another study is recommended with bigger sample size and in depth tools to accurately assess their morbidities.

\section{Acknowledgment}

We would like to thank Syrian refugees' participants, who dedicated their time and attention to participate in this work.

\section{References:}

1. Gjoni, A. A. A. E., Bedjaoui, A. A. R. A., Mangueira, A. A. D. S. A., Graca, J., Sturzenegger, A. L. A. C. F., Hayrapetyan, A. V. G. A., ..., Azam, S. (2015). Governors and Alternates of the World Bank| June 30, 2017. Development, 11.

2. Kirmayer, L.J., Narasiah, L., Munoz, M., Rashid, M., Ryder, A.G., Guzder, J., Hassan, G., Rousseau, C., and Pottie, K. (2011). Common mental health problems in immigrants and refugees: general approach in primary care. CMAJ : Canadian Medical Association Journal, doi:10.1503/cmaj.090292.

3. Turrini, G., Purgato, M., Ballette, F., Nosè, M., Ostuzzi, G., Barbui, C. (2017). Common mental disorders in asylum seekers and refugees: umbrella review of prevalence and intervention studies. International Journal of Mental Health Systems, 11, 51. http://doi.org/10.1186/s13033017-0156-0

4. Mollica, R.F., Sarajlićm N., Chernoff, M., Lavelle, J., Vuković, I.S., Massagli, M.P. (2001). Longitudinal Study of Psychiatric Symptoms, Disability, Mortality, and Emigration Among Bosnian Refugees. JAMA， 286(5):546-554. doi:10.1001/jama.286.5.546

5. Pfarrwaller, E., Suris, J. C. (2012). Determinants of health in recently arrived young migrants and refugees: a review of the literature. Italian Journal of Public Health, 9(3).

6. Bloch, A. (2000). A new era or more of the same? Asylum policy in the UK. Journal of Refugee Studies, 13(1), 29-42. UNHCR, 2018. Syria Regional Refugee response. Retreived at: http://data2.unhcr.org/en/situations/syria/location $/ 1$

7. Poole, D., Hedt-Gauthier, B., Raymond, N., Bärnighausen, T. (2018). Major depression prevalence among Syrian migrants seeking asylum in Greece: a cross-sectional survey. The Lancet Global Health, 6, S20.

8. Acarturk, C., Cetinkaya, M., Senay, I., Gulen, B., Aker, T., Hinton, D. (2018). Prevalence and predictors of posttraumatic stress and depression symptoms among Syrian refugees in a refugee camp. The Journal of nervous and mental disease, 206(1), 40-45.

9. Tinghög, P., Malm, A., Arwidson, C., Sigvardsdotter, E., Lundin, A., Saboonchi, F. (2017). Prevalence of mental ill health, traumas and postmigration stress among refugees from Syria resettled in Sweden after 2011: a population-based survey. BMJ Open, 7(12), e018899. http://doi.org/10.1136/bmjopen-2017018899

10. Kira, I. A., Shuwiekh, H., Rice, K., Al Ibraheem, B., Aljakoub, J. (2017). A Threatened Identity: The Mental Health Status of Syrian Refugees in Egypt and Its Etiology. Identity, 17(3), 176-190.

11. Naja, W.J., Aoun, M.P., El Khoury, E.L., Abdallah, F.J., Haddad, R.S. (2016). Prevalence of depression in Syrian refugees and the influence of religiosity. Compr Psychiatry. 2016 Jul;68:78-85. doi: 10.1016/j.comppsych.2016.04.002. Epub 2016 Apr 6

12. International Labour Organization (ILO). International Standard Classification of Occupations (2012). Retrieved from http://www.ilo.org/wcmsp5/groups/public/--dgreports/---dcomm/---

publ/documents/publication/wcms_172572.pdf 13. Beck, .A.T., Ward, C.H., Mendelson, M., Mock, J., Erbaugh, J. (1961). An inventory for measuring depression. Archives of General Psychiatry, 4:53-63.

14. Abdel-Khalek A. (1996). Beck Depression Inventory: the Arabic version. Cairo, AngloEgyptian Bookshop.

15. Taylor, J. (1953). A Personality Scale of Manifest Anxiety, J Abnorm Psychol. 48 (2): 258-90.

16. Fahmi, M., Ghali,M., Meleka, K. (1977). Arabic version of the personality scale of manifest anxiety, Egyptian Psychiatry. 11: 119126. 
17. World Health Organization. Global Burden Of Diseases 2004 Update. (2008). Geneva: WHO.

18. Perez-Sales, P. (2013). Médecins du monde. Assessment of Trauma Experiences, Mental Health and Individual and Community Coping Resources of Refugee Syrian Population Displaced in North Bekaa, Lebanon.

19. Bischoff, A., Bovier, P. A., Isah, R., Françoise, G., Ariel, E., Louis, L. (2003). Language barriers between nurses and asylum seekers: Their impact on symptom reporting and referral. Social Science \& Medicine, 57(3), 503-512. doi:10.1016/S02779536(02)00376-3.

20. Hadziabdic, E., Heikkilä, K., Albin, B., Hjelm, K. (2009). Migrants' perceptions of using interpreters in health care. International Nursing Review, 56(4), 461-469. doi:10.1111/j.14667657.2009.00738.

21. Hassan, G., Ventevogel, P., Jefee-Bahloul, H., Barkil-Oteo, A., Kirmayer, L. J. (2016). Mental health and psychosocial wellbeing of Syrians affected by armed conflict. Epidemiology and Psychiatric Sciences, 25(2), 129-141. doi:10.1017/S2045796016000044

22. Gammouh, O. S., Al-Smadi, A. M., Tawalbeh, L. I., \& Khoury, L. S. (2015). Peer reviewed: Chronic diseases, lack of medications, and depression among Syrian refugees in Jordan, 2013-2014. Preventing chronic disease, 12.

23. Gerritsen, A.A., Bramsen, I., Deville, W., van Willigen, L.H., Hovens, J.E., van der Ploeg, H.M. (2006). Physical and mental health of Afghan, Iranian and Somali asylum seekers and refugees living in the Netherlands. Soc Psychiatry Psychiatr Epidemiol;41:18-26, http://dx.doi.org/ 10.1007/s00127-005-0003-5.

24. Fazel, M., Wheeler, J., Danesh, J. (2005). Prevalence of serious mental disorder in 7000 refugees resettled in western countries: a systematic review. Lancet; 365:1309-14, http://dx.doi.org/10.1016/s0140- 6736(05)610276.

25. de Jong, J.T., Komproe, I.H., Van Ommeren, M. (2003). Common mental disorders in postconflict settings. Lancet; 361:2128-30, http://dx.doi.org/ 10.1016/s0140-6736(03)136926.
26. Bracken, P.J., Giller, J.E., Summerfield, D. (1995). Psychological responses to war and atrocity: the limitations of current concepts. Soc Sci Med;40: 1073-82.

27. Westermeyer, J., Janca, A. (1997). Language, culture and psychopathology: conceptual and methodological issues. Transcult Psychiatry;34: 291-311, http://dx.doi.org/10.1177/136346159703400301. 28. Bogic, M., Ajdukovic, D., Bremner, S., ,Franciskovic, T., Galeazzi, G.M., Kucukalic, A, ..., Priebe, S. (2012). Factors associated with mental disorders in long-settled war refugees: refugees from the former Yugoslavia in Germany, Italy and the UK. Br J Psychiatry2012;200:216 -23.

29. Söndergaard, H.P., Ekblad, S., Theorell, T. (2003). Screening for post-traumatic stress disorder among refugees in Stockholm. Nord J Psychiatry; 57:185-9.

30. Laban, C.J., Gernaat, H.B., Komproe, I.H., Schreuders, B.A., De Jong, J.T. (2004). Impact of a long asylum procedure on the prevalence of psychiatric disorders in Iraqi asylum seekers in The Netherlands. J Nerv Ment Dis; $192: 843$

51. doi:10.1097/01.nmd.0000146739.26187.15

31. Porter, M., Haslam, N. (2005). Predisplacement and post displacement factors associated with mental health of refugees and internally displaced persons. JAMA.

32. Krupinski, J., Stoller, A., Wallace, L. (1973) Psychiatric disorders in East European refugees now in Australia. Soc Sci Med.

33. Steel, Z., Silove, D., Phan, T., Bauman, A. (2002). Long-term effect of psychological trauma on the mental health of Vietnamese refugees resettled in Australia: a populationbased study. Lancet.

34. Marshall, G., Schell, T., Elliot, M., Berthold, M., Chun, C. (2005). Mental health of Cambodian refugees 2 decades after resettlement in the United States. JAMA.

35. Ager, A., Strang, A. (2004), Indicators of Integration. A Home Office Development and Practice Report. Communication Development Unit, Room 264, Home Office, 50 Queen Anne's Gate, London SW1H 9AT. 